\title{
TU/e emonownen

\section{Solution-processed small molecule transistors with low operating voltages and high grain-boundary anisotropy}

\section{Citation for published version (APA):}

Yu, L., Li, X., Smith, J., Tierney, S., Sweeney, R., Kjellander, B. K. C., Gelinck, G. H., Anthopoulos, T. D., \& Stingelin, N. (2012). Solution-processed small molecule transistors with low operating voltages and high grainboundary anisotropy. Journal of Materials Chemistry, 22(19), 9458-9461. https://doi.org/10.1039/c2jm30893b

DOI:

10.1039/c2jm30893b

Document status and date:

Published: 01/01/2012

\section{Document Version:}

Publisher's PDF, also known as Version of Record (includes final page, issue and volume numbers)

\section{Please check the document version of this publication:}

- A submitted manuscript is the version of the article upon submission and before peer-review. There can be important differences between the submitted version and the official published version of record. People interested in the research are advised to contact the author for the final version of the publication, or visit the $\mathrm{DOI}$ to the publisher's website.

- The final author version and the galley proof are versions of the publication after peer review.

- The final published version features the final layout of the paper including the volume, issue and page numbers.

Link to publication

\section{General rights}

Copyright and moral rights for the publications made accessible in the public portal are retained by the authors and/or other copyright owners and it is a condition of accessing publications that users recognise and abide by the legal requirements associated with these rights.

- Users may download and print one copy of any publication from the public portal for the purpose of private study or research.

- You may not further distribute the material or use it for any profit-making activity or commercial gain

- You may freely distribute the URL identifying the publication in the public portal.

If the publication is distributed under the terms of Article 25fa of the Dutch Copyright Act, indicated by the "Taverne" license above, please follow below link for the End User Agreement:

www.tue.nl/taverne

Take down policy

If you believe that this document breaches copyright please contact us at:

openaccess@tue.nl

providing details and we will investigate your claim. 


\title{
Solution-processed small molecule transistors with low operating voltages and high grain-boundary anisotropy $\dagger$
}

\author{
Liyang Yu, ${ }^{* a b}$ Xiaoran Li, ${ }^{* c d}$ Jeremy Smith, ${ }^{b e}$ Steven Tierney, ${ }^{f}$ Richard Sweeney, ${ }^{a}$ B. K. Charlotte Kjellander, ${ }^{d}$ \\ Gerwin H. Gelinck, ${ }^{d}$ Thomas D. Anthopoulos ${ }^{b e}$ and Natalie Stingelin ${ }^{a b g}$
}

Received 13th February 2012, Accepted 19th March 2012

DOI: $10.1039 / \mathrm{c} 2 \mathrm{jm} 30893 \mathrm{~b}$

\begin{abstract}
We present a new soluble pentacene derivative with ethyl substitutions in the 1,13,14,22 backbone positions to modulate the solubility and film forming properties of this material compared to triisopropylsilylethynyl (TIPS) pentacene. This permits reproducible production of molecularly highly ordered structures that feature average transistor mobilities in excess of $1 \mathrm{~cm}^{2} \mathrm{~V}^{-1} \mathrm{~s}^{-1}$ depending on crystal orientation by careful selection of casting conditions.
\end{abstract}

The current rapid progress in organic electronics is being driven by the possibility of low-cost semiconductors that can be processed over large areas and that display properties (e.g. mechanical flexibility) that are difficult to obtain in silicon-based devices. Critical for the success of organic-based technologies will be the development of materials that can be readily processed from solution, thus allowing the use of common printing and coating techniques including ink-jet printing or spray coating. ${ }^{1,2}$ Acene molecules have demonstrated high charge-carrier mobilities in organic field-effect transistors (OFETs) and it has been shown that they can be solubilised by the addition of bulky side groups to the acene core, a commonly employed example being triisopropylsilylethynyl (TIPS) pentacene. $^{3-6}$ The progress of using TIPS-pentacene and similar molecules has however been inhibited by the fact that it is difficult to control their solidification from solution. As a consequence inhomogeneous thin films are often obtained when using these materials, resulting in low device yields. ${ }^{7}$ This issue can be partly solved by blending the acene with a polymer matrix, but optimal device performance then usually requires top-

${ }^{a}$ Department of Materials, Imperial College London, SW7 2 AZ London, UK.E-mail: l.yu09@imperial.ac.uk; Tel: +44 (0)20 75940849

${ }^{b}$ Centre for Plastic Electronics, Imperial College London, SW7 $2 \mathrm{AZ}$ London, UK

'Department of Chemical Engineering and Chemistry, Technische Universiteit Eindhoven, P.O. Box 513, 5600 MB Eindhoven, The Netherlands.E-mail: x.li@tue.nl; Tel: +31(0)404020495

${ }^{d}$ Holst CentrelTNO, High Tech Campus 31, 5656 AE Eindhoven, The Netherlands

${ }^{e}$ Department of Physics, Imperial College London, SW7 2 AZ London, UK ${ }^{f}$ Merck Chemicals Ltd., University Parkway, Southampton SO16 7QD, $U K$

${ }^{g}$ FRIAS, School of Soft Matter Research, University of Freiburg, 79104 Freiburg, Germany

$\uparrow$ Electronic supplementary information (ESI) available. See DOI: $10.1039 / \mathrm{c} 2 \mathrm{jm} 30893 \mathrm{~b}$ gate architectures. ${ }^{8}$ This is not desirable for manufacturing integrated circuits. In bottom-gate/bottom-contact geometries, blending can lead to severely contact-limited devices caused by the presence of the polymeric matrix, which is often electronically inert or of lower electronic performance. ${ }^{9}$

In this paper, we explore a new candidate acene molecule based on TIPS-pentacene with substitutions in the $1,13,14,22$ positions,${ }^{10}$ i.e. $\beta$-tetraethyl(triisopropylsilylethynyl) pentacene (BTE-TIPS-PEN). Its chemical structure is shown in Fig. 1, inset. The substitutions affect both the solubility and the crystal structure of the molecule. In addition, the solidification rate from solution seems to be significantly enhanced for this pentacene derivative when compared to TIPSpentacene. As a desirable consequence of this, we find a greatly improved film formation from solution on surfaces with a poor wetting property (such as the silane-treated surface of the commonly employed $\mathrm{SiO}_{2}$ dielectric layer ${ }^{11}$ ) when compared to e.g. TIPS-pentacene, enabling the control of crystal growth during solvent evaporation by careful selection of solvents and casting temperatures.

Three different solvents were evaluated. In a first set of experiments, we cast BTE-TIPS-PEN from $0.5 \mathrm{wt} \%$ chloroform solutions at room temperature. This resulted in thin-film architectures comprised of randomly distributed small needles of a length of $\sim 10 \mu \mathrm{m}$. The resulting films were found to be non-continuous, with voids being observed by cross-polarized microscopy (see Fig. S1 $\uparrow$ ). We attribute this unfavourable behaviour to the relatively low

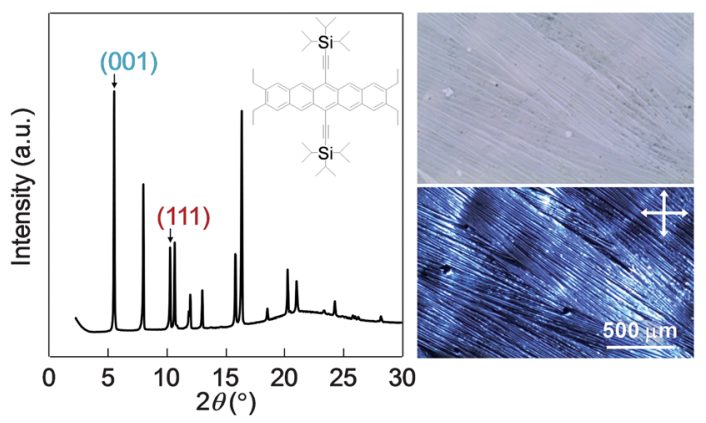

Fig. 1 Left: wide-angle X-ray diffractograms of BTE-TIPS-PEN with its chemical structure as the inset. Right: optical micrographs of BTETIPS-PEN thin films, cast at $120{ }^{\circ} \mathrm{C}$ from $0.5 \mathrm{wt} \%$ xylene solutions (top: bright-field; bottom: crossed-polarized). 
solubility of BTE-TIPS-PEN in chloroform at room temperature, resulting in precipitates already in solution.

In a second set of experiments, we therefore selected decalin as a solvent. Use of this high-boiling-point solvent $\left(T_{\mathrm{b}}=187{ }^{\circ} \mathrm{C}\right)$ permitted us to cast the solutions $(0.5 \mathrm{wt} \%)$ onto a substrate kept at temperatures $>100{ }^{\circ} \mathrm{C}$. This resulted in needle-like structures similar to those observed in certain TIPS-pentacene thin films fabricated by dip coating ${ }^{12}$ or solution casting on tilted substrates, ${ }^{13}$ which indicate a strong one-dimensional growth of the BTE-TIPS-PEN. The latter was strongly dependent on casting temperature: cross-polarized microscopy e.g. reveals an increase of crystal length from $200 \mu \mathrm{m}$ to 3 $\mathrm{mm}$ when varying the solution and substrate temperatures from 100 to $150^{\circ} \mathrm{C}$ (Fig. S1 $\dagger$ ). This is most likely due to an increased solubility of BTE-TIPS-PEN in this solvent at higher temperatures, reducing the number of nuclei in solution.

Interestingly, when we used xylene - another good solvent for BTE-TIPS-PEN - structures comprised of crystals of $20 \mathrm{~mm}$ length were realized already at casting temperatures of $100{ }^{\circ} \mathrm{C}$ (i.e. $50{ }^{\circ} \mathrm{C}$ below the temperatures required for deposition from decalin). Reduced processing temperature is preferred as it minimizes material degradation. ${ }^{14}$ More importantly, the as-cast films featured needles that were surprisingly similar in width $(\sim 5 \mu \mathrm{m})$ and had lengths of up to $20 \mathrm{~mm}$.

Beneficially, the directionality of the strong one-dimensional crystal growth was found to be controllable by tilting the substrate by $\sim 5^{\circ}$ from horizontal while the solution is applied. Consequently, thin films can be produced with a preferred crystal orientation, which provides the possibility of assessing the effect of crystal anisotropy in the thin-film structure on its electronic properties, ${ }^{15-18}$ and making use of this feature in OFET applications. Furthermore, uniaxial orientation of the BTE-TIPS-PEN crystals prevented formation of noticeable voids as is evident from the bright-field and cross-polarized optical micrographs taken at the same location (Fig. 1).

We first characterised the structural anisotropy by wide-angle X-ray scattering (WAXS) powder and texture analysis. From the powder diffraction, we extract the molecular packing and crystal structure of BTE-TIPS-PEN. Similar to TIPS-pentacene, the molecules are packed in a slip-stacked structure. Interestingly, and unlike the common TIPS-pentacene architecture, BTE-TIPS-PEN features slightly tilted $\left(\sim 15^{\circ}\right)$ molecules in opposite direction with respect to the $b$-axis (see Fig. S $\uparrow \dagger$ ). The notable orientational preference of the unit cells is evident in the texture analysis of the (001) and (111) diffractions ( $2 \theta$ of $5.4^{\circ}$ and $9.8^{\circ}$, respectively). The (111) pole figure suggests that the $\pi-\pi$ stacking of the pentacene backbones is along the direction of the needle growth. The (001) pole figure in addition indicates that the $c$-axis is parallel to the normal vector of the substrate surface as deduced from the high intensity diffraction spot in the centre of the graph. Comparison with the unit cell structure seems to imply that the molecules form a highly ordered 2D-structure, where the substituents at the 1,13,14,22 positions are anchored on the substrate with an angle of about $48.8^{\circ}$ to the surface (see the schematic in Fig. 2). This is unlike TIPS-pentacene and other known pentacene and anthradithiophene derivatives for which the molecules generally "stand up" with their central TIPS moiety anchored on the substrate surface. The different orientation of BTE-TIPS-PEN compared to other derivatives may result from the fact that the interactions of the ethyl substituents at the terminal phenyl-ring positions with the substrate are stronger than those of the isopropyl moieties of the TIPS side chain.
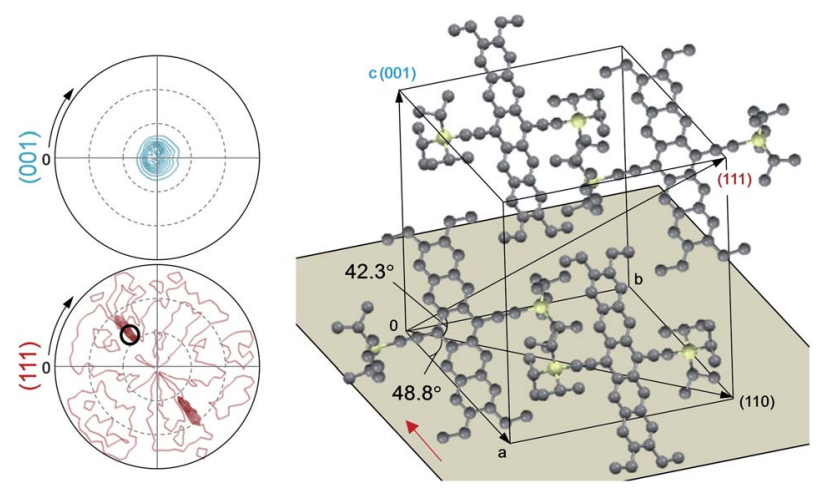

Fig. 2 Left: wide-angle X-ray diffraction (001) and (111) pole figures of BTE-TIPS-PEN thin films. Right: schematic of the unit cell of BTETIPS-PEN structures and its orientation with respect to the substrate (the red arrow indicates the growth direction of the needles). The black circle in the pole figure of (111) diffraction indicates the direction of $\psi=42.3^{\circ}$ and $\varphi=48.8^{\circ}$.

To evaluate the influence of different needle orientations in terms of electronic behaviour, we fabricated bottom-gate/bottom-contact OFETs on $\mathrm{Si}\left(\mathrm{n}^{++}\right) / \mathrm{SiO}_{2}$ substrates with an oxide thickness of $140 \mathrm{~nm}$ and photo-lithographically patterned $\mathrm{Au}$ as source and drain electrodes. Prior to device fabrications, a pentafluorobenzenethiol monolayer was deposited on Au electrodes. ${ }^{19} \mathrm{The}^{\mathrm{SiO}_{2}}$ dielectric was treated with trichlorophenylsilane. ${ }^{20}$

The as-cast thin films comprised of uniaxially aligned BTE-TIPSPEN needles exhibited excellent transistor performance. The transfer characteristics of two typical devices (with identical channel width to (a)

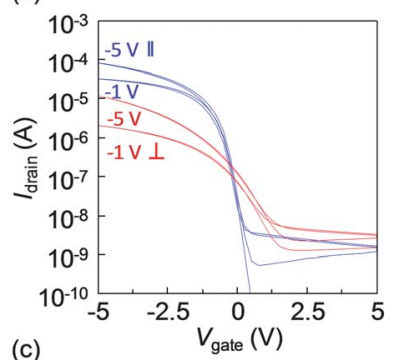

(c)

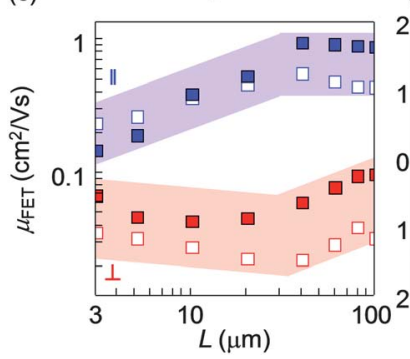

(b)

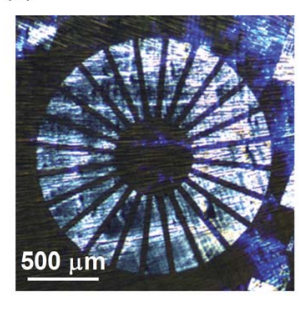

(d)

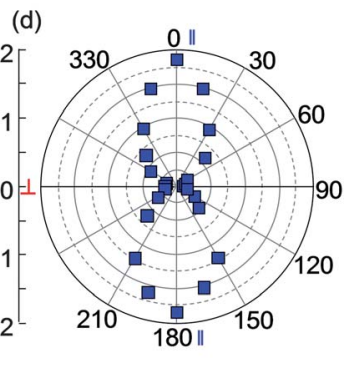

Fig. 3 (a) Typical transfer characteristics of BTE-TIPS-PEN in bottomgate/bottom-contact field-effect transistor configuration $(L=10 \mu \mathrm{m}$; $W$ $=5000 \mu \mathrm{m}$ ), with needles oriented parallel (blue) and perpendicular (red) to the source-drain bias direction. (b) Cross-polarized optical micrograph of a BTE-TIPS-PEN thin film on an "umbrella" transistor configuration. (c) Charge-carrier mobilities $\mu_{\mathrm{FET}}$ of BTE-TIPS-PEN versus transistor channel lengths, $L$ (filled and non-filled symbols represent resp. the saturation and linear $\mu_{\mathrm{FET}}$ ). (d) Polar plot for $\mu_{\mathrm{FET}}$ (linear regime) with respect to the angle between the needles and the sourcedrain bias direction. 
length ratio, W/L) are shown in Fig. 3a. Corresponding output characteristics are supplied in the ESI (Fig. S3†). We compare the two most extreme cases of needle orientation, i.e. OFETs with the BTE-TIPSPEN needle directions being positioned parallel or perpendicular to the direction of the source-drain bias. It is evident from the data displayed in Fig. 3a that both structures result in transistors that are operating at remarkably low voltages $(<5 \mathrm{~V})$ and that display negligible hysteresis between the forward and backward sweeps. For OFETs based on BTE-TIPS-PEN needles positioned parallel to the source-drain bias direction, we find an average saturation mobility of $1.34 \mathrm{~cm}^{2} \mathrm{~V}^{-1} \mathrm{~s}^{-1}$, which is combined with an on/off ratio of over $10^{5}$, a near-zero threshold voltage, and a steep sub-threshold slope $(130 \mathrm{mV}$ per dec). The latter value compares indeed favourably with some of the lowest reported values for organic transistors, ${ }^{9,21,22}$ suggesting a high quality gate-dielectric-semiconductor interface with few charge-trapping centres. ${ }^{23,24}$ Clearly, interfacial trapping is not adversely mitigating charge-transport in these devices. In comparison, devices with BTE-TIPS-PEN needles positioned perpendicular to the direction of source-drain bias displayed significantly lower saturation mobilities $\left(0.1 \mathrm{~cm}^{2} \mathrm{~V}^{-1} \mathrm{~s}^{-1}\right)$, higher threshold voltages, lower on/off ratios $\left(<10^{4}\right)$ and drastically increased sub-threshold slopes (Fig. 3a).

This sharp contrast in almost all device parameters between OFETs fabricated at different needle directions motivated us to study in detail the angular dependence of charge transport of BTE-TIPSPEN and its origin. To this end, we adopted a so-called "umbrella" source/drain configuration where 24 independent transistors are arranged in a circular array (Fig. 3b), ${ }^{25}$ allowing us to measure the device performance with respect to the crystal orientation with an angular resolution of $15^{\circ}$.

A high yield in device fabrication was obtained using this "umbrella structure": among all 132 devices, we measured $\mu_{\mathrm{FET}}$ (linear) of $0.54 \pm$ $0.47 \mathrm{~cm}^{2} \mathrm{~V}^{-1} \mathrm{~s}^{-1}$ and $\mu_{\mathrm{FET}}$ (saturation) of $0.58 \pm 0.47 \mathrm{~cm}^{2} \mathrm{~V}^{-1} \mathrm{~s}^{-1}$, independent of device orientation. By plotting the $\mu_{\text {FET }}$ of a typical array of 24 devices against the crystal orientation with respect to the direction of source-drain bias, a clear angular dependence of the mobilities on the orientation of BTE-TIPS-PEN crystals is found (Fig. 3d). Where the source-drain bias is applied along the needle direction, $\mu_{\text {FET }}$ was found to be $1-2 \mathrm{~cm}^{2} \mathrm{~V}^{-1} \mathrm{~s}^{-1}$ on average $(1.15 \pm$ $0.41 \mathrm{~cm}^{2} \mathrm{~V}^{-1} \mathrm{~s}^{-1}$ and $1.16 \pm 0.44 \mathrm{~cm}^{2} \mathrm{~V}^{-1} \mathrm{~s}^{-1}$ in the linear and saturation regions, respectively), with $\mu_{\mathrm{FET}}$ (saturation) max reaching up to $3.92 \mathrm{~cm}^{2} \mathrm{~V}^{-1} \mathrm{~s}^{-1}$ for the best devices. Note the fact that similar mobility values are deduced in the two regimes, which is indicative of the absence of significant parasitic effects such as contact limitations at this channel length $(40 \mu \mathrm{m})$. The performance is also significantly superior to that of devices of different crystal orientations. Indeed, where the charges are driven by the source-drain bias in a direction perpendicular to the crystal growth direction (i.e. $\perp$ to the needle's long axis), $\mu_{\text {FET }}$ was 20-40 times lower than $\mu_{\text {FET }}$ measured for devices with needles parallel to the direction of source-drain bias. Unlike the anisotropy previously reported for single crystals, ${ }^{25,26}$ however, this orientation dependence of $\mu_{\text {FET }}$ does not fit a simple mobility tensor transformation. This is most likely a result of the effect of in-grain anisotropy in combination with the anisotropy induced by BTE-TIPSPEN needle alignment leading to a more complex angular dependence.

In order to verify this hypothesis, we studied the channel length dependence of our transistors in two extreme cases, i.e. with the BTETIPS-PEN needles positioned at directions parallel or perpendicular to the direction of source-drain bias voltage applied (Fig. 3c). When the needle direction is parallel to the direction of the source-drain bias (blue symbols; $\|$ ), $\mu_{\mathrm{FET}}$ increases with $L$ (up to $L=40 \mu \mathrm{m}$ ), then saturates around $1 \mathrm{~cm}^{2} \mathrm{~V}^{-1} \mathrm{~s}^{-1}$ upon further increase of $L$. This behaviour is most likely due to contact-resistance effects dominating transport in short-channel devices, arising from non-ideal charge injection at the source and drain electrodes. ${ }^{27-30}$ For devices with the BTE-TIPS-PEN needles positioned perpendicular to the source-drain bias (red symbols; $\perp$ ), a somewhat unexpected channel length dependence is observed. At first, there is a notable decrease in mobility as $L$ increases from 3 to $20 \mu \mathrm{m}$, which is particularly pronounced for $\mu_{\mathrm{FET}}$ (linear). Considering that the width of the BTE-TIPS-PEN needles is around $5 \mu \mathrm{m}$, this suggests that at larger channels (in the 5 to $20 \mu \mathrm{m}$ regime), more than one needle is required to fully cover the channel, leading to grain boundaries positioned perpendicular to the source-drain bias within the channel region. This results in an initial reduction of $\mu_{\mathrm{FET}}$; i.e. grain boundaries limit charge transport, not contacts. When however further increasing $L$, the mobility improves again and saturates at a value of $\sim 0.1 \mathrm{~cm}^{2} \mathrm{~V}^{-1} \mathrm{~s}^{-1}$ for $L>50 \mu \mathrm{m}$.

Interestingly, it is also evident from Fig. $3 \mathrm{c}$, that the mobility values are comparable for both needle directions in devices of $L=3 \mu \mathrm{m}$, i.e. for channel dimensions smaller than the width of the grains. This indicates that there is a relatively low intrinsic in-grain anisotropy of $\mu_{\mathrm{FET}}$ (respectively $\sim 2$ and 4 in the saturation and linear regimes), suggesting that more pronounced anisotropy effects arise due to the presence of grain boundaries within the channel region at specific needle orientations. Hence, the high $\mu_{\mathrm{FET}}$ anisotropy is mainly attributed to the geometric morphology (i.e. anisotropy of number of grain-boundaries $^{12,31}$ ) of the BTE-TIPS-PEN needles.

\section{Conclusions}

In summary, we have demonstrated that BTE-TIPS-PEN-a new TIPS-pentacene derivative with substituents in the 1,13,14,22 positions of the pentacene backbone - can be readily fabricated into highperformance OFET structures using a single-step process without the need to form blends or the use of top-gate structures. Average mobilities of more than $1 \mathrm{~cm}^{2} \mathrm{~V}^{-1} \mathrm{~s}^{-1}$ are measured in both the linear and saturation regimes (respectively, $-1 \mathrm{~V}$ and $-5 \mathrm{~V}$ ) for specific crystal orientations, with the highest saturation mobility measured in these devices being as high as $3.92 \mathrm{~cm}^{2} \mathrm{~V}^{-1} \mathrm{~s}^{-1}$. This performance is a notable improvement over TIPS-pentacene previously produced by drop-casting, spin-coating, and ink-jet printing, ${ }^{32}$ and other solutionprocessed acene-based single component devices, ${ }^{33-35}$ confirming that improved molecular engineering results in a controlled micro- and macro-structure of BTE-TIPS-PEN thin films that positively influences the electronic properties. This high level of reproducibility is required for the technological exploitation of such discrete devices in large-area organic electronics. In addition, a complex angular dependence of mobilities was observed for BTE-TIPS-PEN films cast from xylene comprising needles of up to $20 \mathrm{~mm}$ in length $(5 \mu \mathrm{m}$ in width), the origin of which is attributed to a combined effect of in-grain anisotropy in conjunction with the anisotropy given by the BTE-TIPS-PEN needles, resulting in different amounts of grain boundaries depending on the crystal orientation.

\section{Acknowledgements}

We are deeply indebted to John Anthony (University of Kentucky) for many invaluable discussions. We acknowledge Bas van der Putten (Holst Centre) for technical assistance, and are very grateful to the 
UK's Engineering and Physical Sciences Research Council, the Dutch Polymer Institute (LATFE programme) and the EC's 7th Framework Program ONE-P project (Grant Agreement 212311) for financial support.

\section{Notes and references}

1 B. J. de Gans, P. C. Duineveld and U. S. Schubert, Adv. Mater., 2004, 16, 203.

2 N. A. Azarova, J. W. Owen, C. A. McLellan, M. A. Grimminger, E. K. Chapman, J. E. Anthony and O. D. Jurchescu, Org. Electron., 2010, 11, 1960.

3 J. E. Anthony, J. S. Brooks, D. L. Eaton and S. R. Parkin, J. Am. Chem. Soc., 2001, 123, 9482.

4 C. D. Sheraw, T. N. Jackson, D. L. Eaton and J. E. Anthony, $A d v$. Mater., 2003, 15, 2009.

5 S. K. Park, T. N. Jackson, J. E. Anthony and D. A. Mourey, Appl. Phys. Lett., 2007, 91, 063514.

6 G. Giri, E. Verploegen, S. C. B. Mannsfeld, S. Atahan-Evrenk, D. H. Kim, S. Y. Lee, H. A. Becerril, A. Aspuru-Guzik, M. F. Toney and Z. Bao, Nature, 2011, 480, 504.

7 J. H. Chen, D. C. Martin and J. E. Anthony, J. Mater. Res., 2007, 22, 1701.

8 R. Hamilton, J. Smith, S. Ogier, M. Heeney, J. E. Anthony, I. McCulloch, J. Veres, D. D. C. Bradley and T. D. Anthopoulos, Adv. Mater., 2009, 21, 1166.

9 X. Li, W. T. T. Smaal, C. Kjellander, B. van der Putten, K. Gualandris, E. C. P. Smits, J. Anthony, D. J. Broer, P. W. M. Blom, J. Genoe and G. Gelinck, Org. Electron., 2011, 12, 1319.

10 J. Jiang, B. R. Kaafarani and D. C. Neckers, J. Org. Chem., 2006, 71, 2155.

11 H. Ma, H. Yip, F. Huang and A. K. Y. Jen, Adv. Funct. Mater., 2010, 20, 1371 .

12 C. W. Sele, B. K. C. Kjellander, B. Niesen, M. J. Thornton, J. B. P. H. van der Putten, K. Myny, H. J. Wondergem, A. Moser, R. Resel, A. J. J. M. van Breemen, N. van Aerle, P. Heremans, J. E. Anthony and G. H. Gelinck, Adv. Mater., 2009, 21, 4926.

13 W. H. Lee, D. H. Kim, Y. Jang, J. H. Cho, M. Hwang, Y. D. Park, Y. H. Kim, J. I. Han and K. Cho, Appl. Phys. Lett., 2007, 90, 132106.

14 J. H. Chen, S. Subramanian, S. R. Parkin, M. Siegler, K. Gallup, C. Haughn, D. C. Martin and J. E. Anthony, J. Mater. Chem., 2008, 18, 1961

15 B. O’Connor, R. J. Kline, B. R. Conrad, L. J. Richter, D. Gundlach, M. F. Toney and D. M. DeLongchamp, Adv. Funct. Mater., 2011, 21, 3697.
16 X. Zhang, L. J. Richter, D. M. DeLongchamp, R. J. Kline, M. R. Hammond, I. McCulloch, M. Heeney, R. S. Ashraf, J. N. Smith, T. D. Anthopoulos, B. Schroeder, Y. H. Geerts, D. A. Fischer and M. F. Toney, J. Am. Chem. Soc., 2011, 133, 15073.

17 A. Salleo, R. J. Kline, D. M. DeLongchamp and M. L. Chabinyc, Adv. Mater., 2010, 22, 3812.

18 I. McCulloch, M. Heeney, M. L. Chabinyc, D. DeLongchamp, R. J. Kline, M. Cölle, W. Duffy, D. Fischer, D. Gundlach, B. Hamadani, R. Hamilton, L. Richter, A. Salleo, M. Shkunov, D. Sparrowe, S. Tierney and W. Zhang, Adv. Mater., 2009, 21, 1091.

19 M. M. Payne, S. R. Parkin, J. E. Anthony, C. C. Kuo and T. N. Jackson, J. Am. Chem. Soc., 2005, 127, 4986.

20 X. Li, B. K. C. Kjellander, J. E. Anthony, C. W. M. Bastiaansen, D. J. Broer and G. H. Gelinck, Adv. Funct. Mater., 2009, 19, 3610.

21 V. Podzorov, S. E. Sysoev, E. Loginova, V. M. Pudalov and M. E. Gershenson, Appl. Phys. Lett., 2003, 83, 3504.

22 M. Halik, H. Klauk, U. Zschieschang, G. Schmid, C. Dehm, M. Schutz, S. Maisch, F. Effenberger, M. Brunnbauer and F. Stellacci, Nature, 2004, 431, 963.

23 S. H. Kim, D. Choi, D. S. Chung, C. Yang, J. Jang, C. E. Park and S.-H. K. Park, Appl. Phys. Lett., 2008, 93, 113306.

24 K. Myny, S. De Vusser, S. Steudel, D. Janssen, R. Muller, S. De Jonge, S. Verlaak, J. Genoe and P. Heremans, Appl. Phys. Lett., 2006, 88, 222103.

25 C. Reese and Z. Bao, Adv. Mater., 2007, 19, 4535.

26 V. C. Sundar, J. Zaumseil, V. Podzorov, E. Menard, R. L. Willett, T. Someya, M. E. Gershenson and J. A. Rogers, Science, 2004, 303, 1644.

27 H. Sirringhaus, Adv. Mater., 2005, 17, 2411.

28 E. Meijer, G. Gelinck, E. van Veenendaal, B. Huisman, D. de Leeuw and T. Klapwijk, Appl. Phys. Lett., 2003, 82, 4576.

29 L. Bürgi, H. Sirringhaus and R. H. Friend, Appl. Phys. Lett., 2002, 80, 2913.

30 R. A. Street and A. Salleo, Appl. Phys. Lett., 2002, 81, 2887.

31 J. Rivnay, L. H. Jimison, J. E. Northrup, M. F. Toney, R. Noriega, S. Lu, T. J. Marks, A. Facchetti and A. Salleo, Nat. Mater., 2009, 8, 952.

32 J. A. Lim, H. S. Lee, W. H. Lee and K. Cho, Adv. Funct. Mater., 2009, 19, 1515 .

33 D. J. Gundlach, J. E. Royer, S. K. Park, S. Subramanian, O. D. Jurchescu, B. H. Hamadani, A. J. Moad, R. J. Kline, L. C. Teague, O. Kirillov, C. A. Richter, J. G. Kushmerick, L. J. Richter, S. R. Parkin, T. N. Jackson and J. E. Anthony, Nat. Mater., 2008, 7, 216.

34 G. R. Llorente, M. B. Dufourg-Madec, D. J. Crouch, R. G. Pritchard, S. Ogier and S. G. Yeates, Chem. Commun., 2009, 3059.

35 Q. Meng, H. Dong, W. Hu and D. Zhu, J. Mater. Chem., 2011, 21, 11708 . 